\title{
Automated control complexes of the tillage units operation
}

\author{
Sergey Starovoitov ${ }^{1, *}$, Badri Akhalaya ${ }^{1}$, Yulia Tsench $^{1}$, Sergey $\operatorname{Kvas}^{1}$, Andrey Zolotarev ${ }^{1}$ \\ ${ }^{1}$ Federal Scientific Agroengineering Center VIM, 5, 1st Institutskiy proezd, 109428, Moscow, Russia
}

\begin{abstract}
The authors showed that a further productivity increase and an improvement in the tillage quality require the use of automated control systems for the tillage units operation. (Research purpose) To make a structural components analysis of a complex of tillage units automated control. (Materials and methods) The authors used scientific and technical information and patent literature. They made a structural components analysis of an automated control system of the tillage units operation.(Results and discussion) The authors showed that the system for assessing the technical condition of a tillage can use a vision system and tensometric equipment. The adaptive functional configuration system involves the use of a system for scanning the subsoil layer, technical vision, and tensometric equipment. One of the most important aspects of the stability of the technological process is the development of conditions for the formation of a self-fulfilling traction line. (Conclusions) Tensometric equipment, a vision system, and ultrasound scanning can be used as systems included in the automated control complexes of the tillage units operation. The functioning of these systems should be based on the operation of a neural network, linking the soil cultivation quality indicators and the implement kinematic parameters in a joint complex.
\end{abstract}

\section{Introduction}

Issue status. The main factor of increasing the agriculture efficiency is the introduction of modern technologies based on highly efficient agricultural machinery. The agricultural machines increasing complexity, the conditions for their use, the increasing demands on the technological process quality, all these demand new approaches and concepts, including "Precision Agriculture", "Reasonable Agriculture", "Intelligent Agriculture", digitalization and the Internet of objects.

Advanced US farms have a computer with high-speed Internet access, ready-made soil samples analysis (98\%), yield maps, GPS navigation systems $(\sim 80 \%)$, and differential fertilizer (VR) technologies in their technical equipment. Prescriptionmaps are used by more than $60 \%$, and satellite imagery and vegetative index analysis of plants are used by more than $30 \%$ of farmers.

\footnotetext{
*Corresponding author: Starovoitov.si@mail.ru
} 
In Europe $70-80 \%$ of agricultural machinery are sold with integrated smart and navigation systems, while the number of "connected" equipment is at the level of $25 \% \ldots$ $30 \%$.

A further increase in productivity and an improvement in the tillage quality requires the use of automated control systems for the tillage units operation [1] - [2].

The development of automated control systems of the tillage units operation is carried out both in the Russian Federation and abroad.

Automated control systems for the tillage units operation, depending on the adopted soil cultivation technology [3], may include the following systems: ensuring the course stability, adaptive functional configuration, evaluating the quality of the technological process and technical condition, data storage and transmission system.

\section{Research purpose}

To make a structural components analysis of a complex of tillage units automated control.

\section{Materials and methods}

The authors used scientific and technical information and patent literature. They made a structural components analysis of an automated control system of the tillage units operation.

\section{Research results}

The technical condition assessment system can evaluate the condition of the most loaded load-bearing structures made of rolled steel of various profiles and connected by welding, bolts and rivets. In the process of individual elements defects occurrence, deformation of the entire frame is possible, which causes a malfunction of the transmission mechanisms, the location of the working bodies, and this, in turn, leads to a decrease in the work quality. For these purposes, we can use either tensometric equipment or a system of technical vision.

The second most important point is the control of the cutting edges wear. For machines with active working bodies, in particular for milling cutters, the control is possible by the deviation of the working torque from the value of the nominal torque for the soil of a certain particle size distribution with a similar kinematic mode indicator and processing depth, absolute humidity value.

For tillage machines with passive and combined working bodies, this indicator can be the deviation of the traction resistance working value from the nominal value for soils with a certain particle size distribution, absolute moisture, processing depth and movement speed. Thus, the cutting edges wear control can be ensured by the use of tensometric equipment.

The data storage and transmission system should transfer integrated technological parameters to the dispatch center server [4], enter data on all indicators in the archive in an accessible format, transfer control commands to adjust the technological process to executors [5]. The implementation of all these three points can be carried out on the basis of wireless communications cloud data (near, middle, far). The modern development of microprocessor technology allows not only to automate the research process, to increase the accuracy of measurements, but also to transmit data to a remote server simultaneously with the preliminary processing of the received information. 
The adaptive functional configuration system provides the implementation of two points: automatic configuration to the transport position and adaptive functional configuration of various degrees of complexity.

Kuhn-Huard company offers [12] an electronic two-part plow control system. One of them is a unit that includes a programmable computer and a control panel, located in the tractor cabin. The second part is an electronic-hydraulic and measuring-adjusting device. When plowing at the end of each furrow, the tractor driver presses a button on the control panel and automatically sequentially lifts the first body, then the last one, followed by rotation of the reversible plow frame.

The first degree of complexity of the adaptive functional configuration system involves automatically changing the angle of disks attack, the angle between the cutting edge and the furrow wall of the ploughshare, the angle between the share and the furrow bottom, and the cutting angle of the subsoiler working body.

We have developed a schematic diagram of an automated device for soil compaction (fig. 1). The device includes a bracket 1 , on which there are two rollers 2, an L-shaped bracket 3, a horizontal cross part 4, which is pivotally connected to the tillage unit frame 5 . On the frame 5, a stand 6 is rigidly fixed, to which an elastic cantilever plate 7 is also rigidly fixed. On the elastic rigidly fixed plate 7 is placed the upper link 10 of the loading cup 9. On the horizontal cross part 4 of the g-shaped bracket 3, the lower link 11 of the loading cup 9 is placed.

The hydraulic cylinder 8 is pivotally connected to the stand 6 of the frame 5 of the tillage unit and the loading cup 9. A level sensor 12 is placed on the horizontal cross member of the 4-shaped bracket 3, which is connected to the electric well (is not shown in the figure).

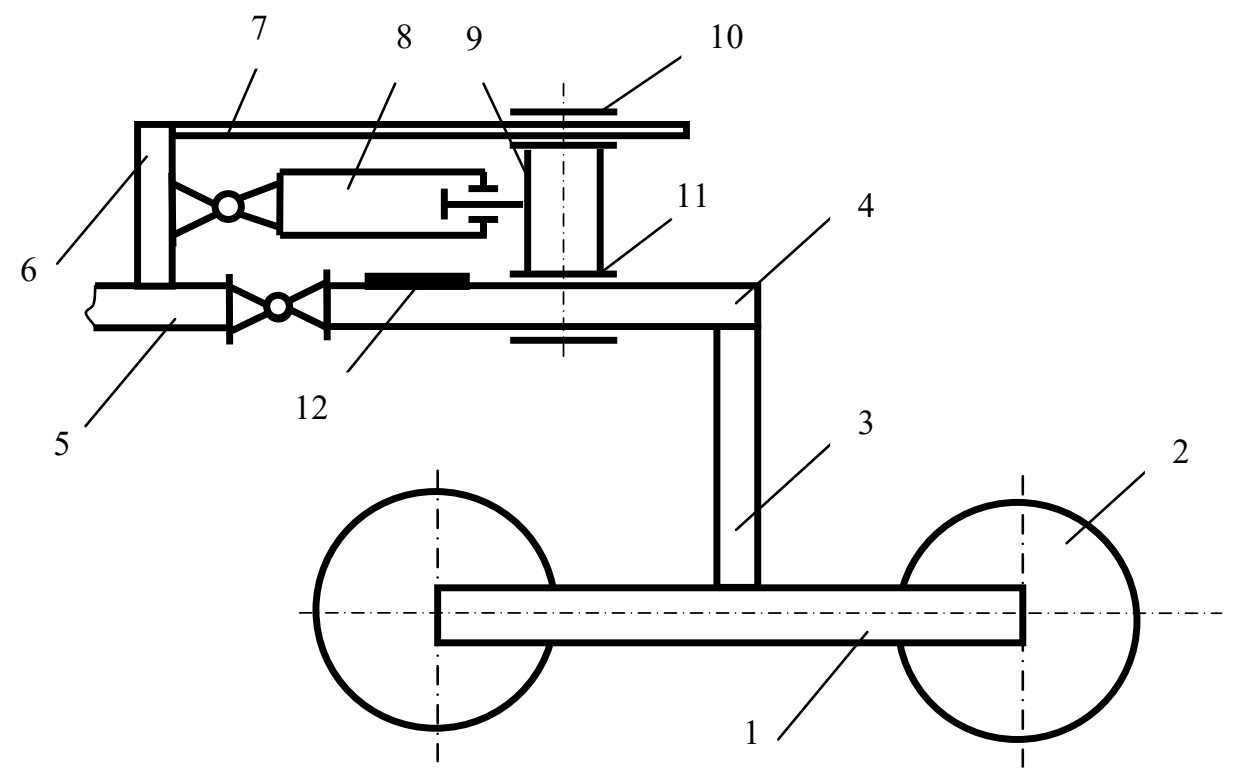

Fig.1. Automated device for soil compaction.

The device operates as follows. During the tillage unit operation, the roller attachment moves along the surface of the field. In loose soil, which must be better compacted, the rollers 2 are deeper immersed in the surface layer. This immersion changes the level sensor 12 position, located on the horizontal cross member 4 of the g-shaped bracket 3 . The level sensor 12 is connected to the electroshock (is not shown in the figure), which gives the 
hydraulic cylinder 8 command, and, in turn, reduces the console length of the elastic plate 7 , moving the loading cup 9 with the upper link on the elastic plate 7 and the lower link on the horizontal cross member 4 . Reducing the console length of the elastic plate 7 allows to tighten the elastic plate 7 , thereby ensuring the transfer of part of the soil abutting equipment weight on a roller annex. With denser soil, the rollers 2 of the roller set-top box are deepened, the level sensor 12 is horizontal, the hydraulic cylinder 8 moves the load cup 9 with the wings to the right, thereby unloading the rollers of the roller set-top box.

The second degree of complexity, for example, takes into account the possibility of transforming the working body that performed the main tillage to a minimum. The implementation of the adaptive functional configuration system of the first complexity can be carried out on the analysis basis of energy intensity or the quality indicators analysis of using machine vision systems. The implementation of the adaptive functional configuration system of the second complexity can be carried out on the basis of monitoring the structure of the processed layer, in particular by the turf thickness.

A system for assessing the soil cultivation quality should control the working bodies depth, the crumbling degree and plant residues embedding, and the surface roughness amount.

In 2018, Topcon Positioning Systems (USA) introduced the ISOBUS compliant NORAC Tillage Depth Control system based on ultrasonic sensors.

When the unit moves, the sensor measures the distance to the ground. Based on the tractor's field passes and sensor readings, the software builds a map of the processing depth based on averaged values. It can be used to evaluate the processing depth uniformity on the field and identify areas with a technology violation. The system automatically maintains the specified processing depth in the conditions of various types of soils and reliefs. Ultrasonic sensors clearly differentiate the soil from plant debris. The processing depth is set via the on-board computer, including along the movement direction.

In 2015 JohnDeere (USA) introduced the TruSet TM TillageTechnology automated system, which began to be installed on the company's tillage equipment. The operator before starting work, set the depth of the lancet paws with an accuracy of $2.5 \mathrm{~mm}$ and disk working bodies, adjusted the force of the packer roller. During the tillage unit operation, data is collected that can be represented in the form of maps. The TruSet ${ }^{\mathrm{TM}}$ TillageTechnology automated system uses position and pressure sensors [US 8573319 B1 of 05.11.2013].

Federal Scientific Agroengineering Center VIM also develope a system for processing depth automated control. This system (Fig. 2) includes reed switches 1 and 2, a local source of magnetic field 3, a control unit 4, an actuator 5, a working body 6 . 


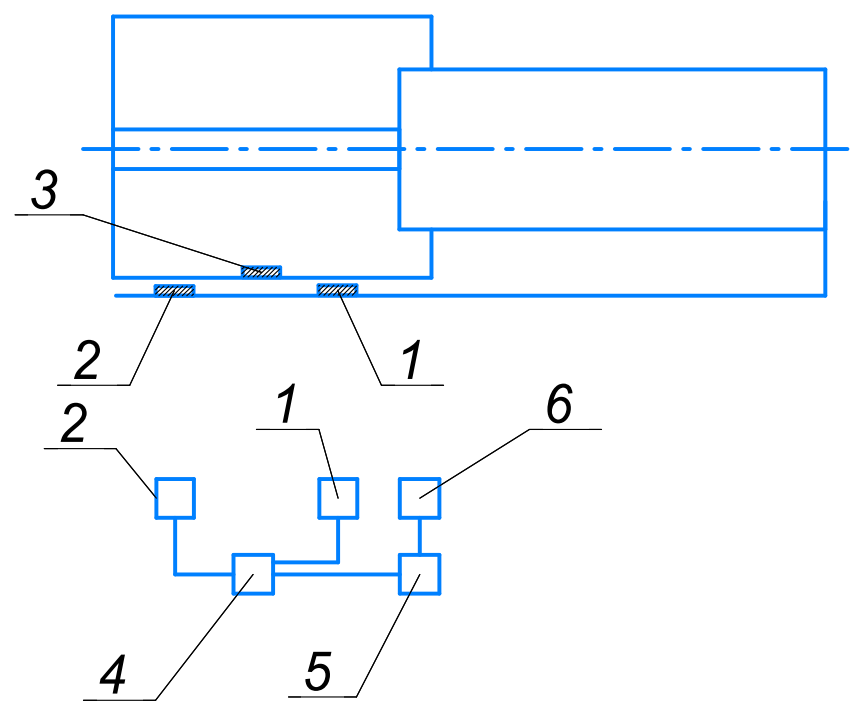

Fig. 2. The system of automated processing depth control.

Reed switch 1 is responsible for the permissible minimum tillage depth, reed switch 2 for the permissible maximum tillage depth. The local source of magnetic field 3 closes the circuit of the control unit 4 of the actuator 5 of the working body 6 [8].

In 2017 Gates Manufacturing (USA) received a patent [US 9668399 B2 06.06.2017] for a Dynamic Adapt Soil Conditioning System. The system includes photosensors, a control unit. Data transmission is carried out via $\mathrm{Wi}-\mathrm{Fi}$ in real time. The control unit changes the attack angle of the disks from 0 to 15 degrees with a step size of 0.5 degrees.

In Iran the methodology of texture analysis using artificial neural networks was used to assess soil crumbling [6]. The neural network in real time evaluated the crumbling quality with subsequent adjustment of the tractor speed and the cultivation depth .

A group of Austrian scientists [7] developed a system for controlling the frequency of active working bodies rotation based on a surface roughness analysis. This parameter was determined using a machine vision system, which included stereo cameras mounted on the front beam of the frame.

A schematic diagram of an automated milling cultivator with a hydraulic drive of the working bodies is known.

To determine the amount of surface combing, the IP-284 device can be used, which consists of a coordinate rail, a movable carriage, two tripods for regulating the horizontal position of the coordinate rail, an integrated laser range finder, an electronic unit for programmatically controlling the movement of the carriage and measuring distances from the coordinate rail horizontal position to soil laser range finder. The information exchange between the electronic unit, rangefinder and laptop is carried out wirelessly via Bluetooth. The GPS module included in the electronic unit allows snapping to the territory for the possibility of repeated measurements over one or several seasons [8].

Various methods are used to assess the degree of conservation or incorporation of crop residues: from traditional ones, such as the linear transect method, to the most advanced using smartphones [10], drones [15] - [11] and remote sensing [12].

Studies [10] show that mobile devices equipped with a camera and applications can perform an adequate digital analysis of crop residues, especially for fields with a low level of residues (less than $30 \%$ of the surface), i.e. in the case of traditional tillage.

It is also possible to carry out similar residues assessment in the field using cameras mounted on the tractor. It is assumed that this indicator will be adjusted manually or 
automatically. An application for this invention was filed by John Deere [US 2017/0112043 A1 27.04.2017].

The system for ensuring the stability of the agricultural implement course can ensure the horizontal frame of the technical device, generate a self-realizing traction line, and adjust the working width taking into account the optimal speed.

Kverneland developed an electronic system that automatically adjued the working width and the working depth.

The stability control system of the technological process ensures the angle of frame inclination in the longitudinally-vertical and transverse-vertical plane, a self-realizing traction line taking into account the properties of the soil and the degree of cutting edges wear using the levels (position sensors). The operation of a self-fulfilling traction line is possible through the use of tensometric equipment.

Massey Ferguson and the Italian company MCElektronica developed a control system for adjusting the position of the plow frame. Huard's electronic control system also provides adjusting the horizontal position of the plow frame. For these purposes, angle sensors are used [19]. In the presence of angle sensors, it becomes possible to control mechanisms and equipment effectively, the operation of which is technologically related to deviations from the vertical axis.

A perspective way to reduce traction on the tractor and automatically maintain stable motion of the field unit in the horizontal plane is to supply the plow with drive support wheels. Plow driving wheels create additional traction moment and unload the tractor. With a stable unit movement, the tractor translational speeds and the wheels-propellers of the plow should be the same. This is supported by adjusting the rotation speed of the propulsion wheels by an automatic system. In this case, the sensor mounted on the field board of the last plow body should show the minimum pressure of the board on the furrow wall. In the event of soil conditions changes the pressure on the field board of the last building increases sharply. This is detected by the field sensor and transmitted to the speed control system of the plow's propulsion wheels.

In the future, it is necessary to create tillage aggregates of electromechanical action, the working process of which would be carried out on the basis of electric energy. The working bodies technological impact of such machines on the material being processed can remain purely mechanical, and electric energy must bring them into action. The working bodies moving relative to the machine frame must rotate. Their optimal angular velocity should correspond to the rotational speed of the electric motor rotor.

\section{Research results discussion}

As systems included in automated control complexes of the tillage units operation, tensometric equipment, a vision system, and ultrasound scanning can be used.

For plows, the use of tensometric equipment will make it possible to realize the possibility of changing the angle between the cutting edge and the furrow wall, to provide control of blade wear and the functioning of a self-realizing traction line.

For implements equipped with disk working bodies, a system of technical vision is acceptable, providing a change in the attack angle of the disks and the sections solution of the disk batteries, affecting the degree of plant debris incorporation. It also makes sense to use tensometric equipment to change the solution angle of disk batteries in order to achieve the optimal combination of the working width of the tillage implement and its speed.

For cultivators, where it is required to ensure sufficient accuracy of the processing depth, it is necessary to introduce ultrasound scanning and use a vision system. 
Wide-grip combined units must be equipped with position sensors that control the frame position, and use the vision system to diagnose the most loaded load-bearing structures of the frame.

For machines with active working bodies, in particular for milling cutters, it is advisable to use a system of technical vision, which will link the degree of crumbling of the soil and the surface roughness with the working body rotational speed. The vision system should be based on the neural network operation, which combines processing quality indicators and kinematic parameters of a tool into a single complex.

\section{Conclusions}

1. As systems included in the automated control complexes of the tillage units operation, tensometric equipment, a vision system, and ultrasound scanning can be used.

2. The functioning of these systems should be based on the neural network operation, linking in a single complex indicators of the soil cultivation quality and the implement kinematic parameters.

3. Automated control complexes of the tillage units operation should provide the adaptive functional configuration systems functioning of varying degrees of complexity.

\section{References}

1. V.A. Sakun, Patterns of mobile agricultural equipment development (Kolos, Moscow, 1994)

2. C.P. Baillie, J.A. Thomasson, C.R. Lobsey, C.L. McCarthy, D.L. Antille, Sensing technologies for optimization of machine operation and farm inputs (2018) DOI: 10.13031/aim.201801589

3. A. Bechar, C. Vigneault, Biosystems Engineering 149, 94-111 (2016) DOI: 10.1016/j.biosystemseng.2016.06.014.

4. A.Y. Izmajlov, Y.P. Lobachevskij, V.K. Horoshenkov, I.G. Smirnov, N.T. Goncharov, E.S. Luzhnova, Sel'skohozyajstvennye mashiny i tekhnologii 3, 4-11 (2018)

5. C.P. Baillie, C.R. Lobsey, D.L. Antille, C.L. McCarthy, J.A. Thomasson, ASABE Annual International Meeting, American Society of Agricultural and Biological Engineers, 1801591 (2018) DOI: 10.13031/aim.201801801591

6. F.R. Ajdadi, Y.A. Gilandeh, K. Mollazade, P.R. Hasanzadeh, Soiland Tillage Research 162, 8-17 (2016) DOI: 10.1016/j.still.2016.04.012

7. P. Riegler-Nurscher, G. Moitzi, J. Prankl, J. Huber, J. Karner, H. Wagentristl, M. Vincze, Soil and Tillage Research 196, 1-9 (2020) DOI: 10.1016/j.still.2019.104351.

8. M. Zagórda, T. Juliszewski, P. Kiełbasa, P. Nawara, T. Dróżdż, K. Trzyniec, Elektrotechniczny 93(12), 199-202 (2017) DOI: 10.15199/48.2017.12.50

9. Novokuban branch of the Federal State Budgetary Institution "Rosinformagrotech", http://www.kubniitim.ru/

10. A. Laamrani, R.P. Lara, A.A. Berg, D. Branson, P. Joosse, Sensors 18(3), 708 (2018) DOI: $10.3390 / \mathrm{s} 18030708$.

11. Z. Kavoosi, M.H. Raoufat, M. Dehghani, A. Jafari, S.A. Kazemeini, M.J. Nazemossadat, Journal of the Saudi Society of Agricultural Sciences 60(4) (2017)

12. B. Zheng, J.B. Campbell, G. Serbin, J.M. Galbraith, Soiland Tillage Research 138, 26$34(2014)$ 
13. V.F. Fedorenko, D.S. Buklagin, N.P. Mishurov, I.G. Golubev and others, Perspective technology for the agro-industrial complex (FGNU «Rosinformagrotekh», Moscow, 2009)

14. A.Yu. Izmajlov, Ya.P. Lobachevskij, A.A. Artyushin, I.G. Smirnov and others, Guidelines for the implementation of monitoring systems and management of harvesting and transport complexes (VIM, Moscow, 2016) 